\title{
EDITORIAL
}

\section{Celebrating 10 years}

$\mathrm{N}$ ovember 2014 is a special month for Nature Reviews Gastroenterology \& Hepatology as it marks 10 years since the launch of the journal in 2004, originally as Nature Clinical Practice Gastroenterology \& Hepatology. So get out the party poppers, take a slice of birthday cake and celebrate in style as we present our $10^{\text {th }}$ Anniversary issue.

It is hard to believe that we have already reached our first decade. The number 10 holds much significance: it graces a certain black doorway on Downing Street, it is on the back of shirts of playmakers and creative midfielders in football teams worldwide, it is the double figures of our current 2013 ISI Impact Factor (10.807). Reaching this important milestone is a testament to all that have been involved in the journal throughout the years and now seems an apt time to pause and reflect on where we have come from as well as look forward to the future.

This celebratory Editorial could not be written if it were not for the efforts of our former Chief Editor, Natalie Wood. Natalie worked with our inaugural (and only) external Editor-in-Chief Stephen B. Hanauer (2004-2010) and the Advisory Board to not only launch the journal, but to nurture and establish it during her tenure (2004-2014) as the leading Review journal in the gastroenterology and hepatology field-it was with a heavy heart that we said goodbye to Natalie in August 2014 and I am delighted to share her thoughts with us now. "During my 10 years heading up the in-house team, I had the pleasure and privilege to meet and work with many world-renowned gastroenterologists and hepatologists, and their generosity with their time and willingness

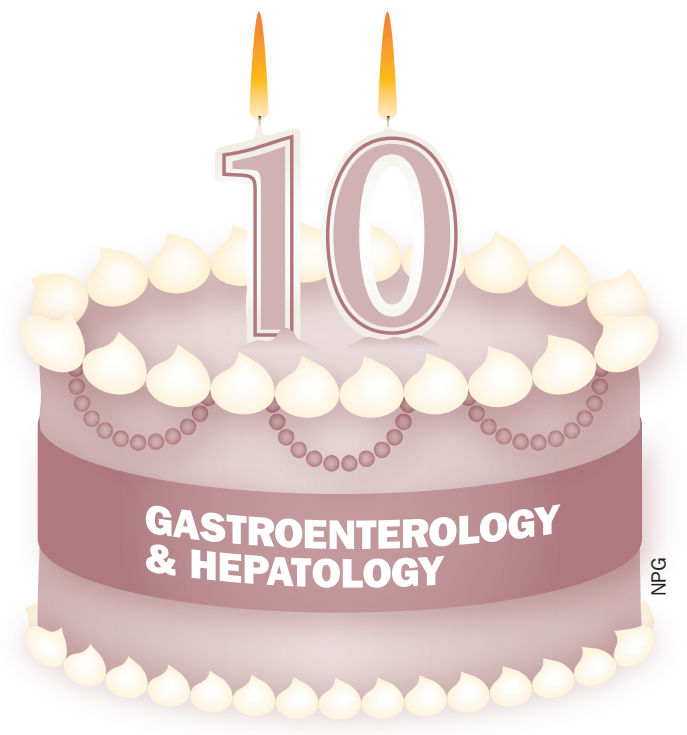

to share ideas never ceased to amaze me," she exclaims. "The way in which our contributors (be they authors, peer-reviewers, Editor-in-Chief, Advisory Board or friends of the journal) and audience embraced the journal undoubtedly lies at the heart of its success to date and will ensure its position in future years, as will the continued passion and dedication of the in-house team."

Launched 10 years ago, our mission was clear: provide easy-to-read, timely, thought-provoking, authoritative articles of the highest quality across the breadth of gastroenterology and hepatology to help maintain and expand the clinical and translational scientific knowledge of our readers. In an Editorial published in our very first issue, Stephen B. Hanauer questioned the need for another journal. At the time he reasoned "despite the proliferation of specialty journals and web-based medical publications, there remains a need for high-quality relevant information in a format that is convenient for clinicians". These sentiments are still true to this day, if not more so. Scientific publishing continues to evolve rapidly, and we now live in a world of instant news and a continuous stream of data. With this onslaught of information, our goal to act as a filter to help busy clinicians and researchers keep up-to-date on the latest scientific and clinical literature is increasingly important.

Much has changed in the fields of gastroenterology and hepatology during this past decade. As such, we asked members of our esteemed Advisory Board to help summarize these major advances and provide predictions for the future. Six special Decade in Review articles look back at progress across six broad topics: gut microbiota; hepatitis C; pancreatic disease; functional gastrointestinal disorders; IBD; and liver cancer (hepatocellular carcinoma in particular). In addition, a Viewpoint article examines the past, present and future of the field. Finally, we put together a special infographic to provide a snapshot of 10 years of the journal in numbers, from the number of online views each month to the number of hours of editorial toil for each issue!

We thank you all for your continued support and would love to hear your thoughts on what the future of gastroenterology and hepatology might hold, so do contact us (via Twitter@NatRevGastroHep). The journal continues to evolve-new formats (mobile, $\mathrm{iPad}^{\circledR}$ [Apple, Cupertino, USA], online and in print), new authors, new areas of interest (such as the gut microbiota and enteric nervous system) - and I hope that the next decade will be just as exciting as the past one. Here's to the next 10 years!

doi:10.1038/nrgastro.2014.175

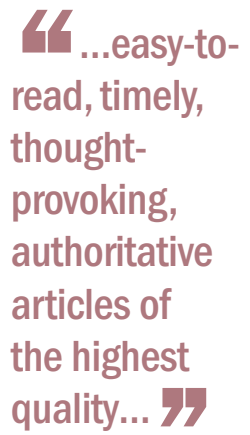

Katrina Ray is the Chief Editor of Nature Reviews Gastroenterology \& Hepatology.

Competing interests The author declares no competing interests. 